\title{
GESTÃO DO CONHECIMENTO: DESVENDANDO A TECNOLOGIA
}

\section{Maira Petrini}

Escola de Administração de Empresas de São Paulo, Fundação Getulio Vargas

Fernando Norte, gerente de desenvolvimento tecnológico, e Natália Alves, diretora administrativa da Rizoma Equipe de Análise e Consultoria - empresa de consultoria situada em Belo Horizonte, Minas Gerais - encontravam-se na frente de seus computadores compartilhando uma sessão de conversa virtual através de um programa Messenger.

A 600 quilômetros dali, em São Paulo (Capital), o diretor de projetos da empresa, Augusto Galery, que recentemente se mudara para essa cidade, era convidado a compartilhar a sessão. Em pauta: como manter a produção de conhecimento entre os dois diretores da empresa, vital para seu funcionamento, mesmo com essa distância entre eles?

\section{Rizoma Consulting}

A micro-empresa Rizoma Equipe de Análise e Consultoria foi formada em 2000, em Belo Horizonte, capital de Minas Gerais, para atuar no setor de consultoria em Psicossociológica e em Gestão de Pessoas. Seus dois sócios, Natália Alves (diretora administrativa) e Augusto Galery (diretor de projetos), ambos psicólogos, utilizavam, para o desenvolvimento de suas atividades, novas teorias de gestão em conjunto com a teoria psicossociológica. No ano seguinte, passaram a investir em ferramentas tecnológicas que os auxiliassem em seus projetos.

\section{CFGV-EAESP/RAE 2010}

Todos os direitos reservados. Permitida a citação parcial, desde que identificada a fonte. Proibida a reprodução total. Em caso de dúvidas, consulte a Redação: gvcasos.redacao@fgv.br; (11) 3799-3717 
Em 2002, a empresa passou por uma reestruturação, voltando-se totalmente para a atuação e assessoria em projetos de Responsabilidade Social Empresarial. Foi criado o Guia Acessível, revista voltada à inclusão social de pessoas portadoras de deficiência e pessoas da terceira idade. Esta revista foi concebida como parte de um projeto multimídia maior, ainda em implantação, chamado Projeto Circulação, que pretende contemplar, além da mídia impressa (revista) e eletrônica (website e newsletter), programas de rádio e televisão. O foco desse projeto é a divulgação de atividades e práticas em Responsabilidade Social. No contexto desta reestruturação, outras modificações foram implementadas pelos dois sócios diretores da empresa como a modernização da logomarca e a mudança no nome da empresa, a qual passou a usar o nome fantasia Rizoma Consulting.

Ao mesmo tempo que montava esse projeto, a empresa começou a oferecer serviços de consultoria para implantação de projetos de responsabilidade social. Nos últimos dez anos, tem crescido muito a preocupação com tal tema: o gerenciamento social e a empresa ética, comprometida com a comunidade onde se insere e com o meio ambiente. É importante notar que a questão estratégica parece ser o principal motivo para o investimento na área social, uma vez que tais empresas, ao serem reconhecidas pela sociedade como socialmente responsáveis, podem conseguir diferenciais de competitividade. A valorização de sua imagem, nesse campo de atuação, tende a aumentar a motivação dos funcionários no trabalho (a empresa consegue melhorar a produtividade), além de ter impacto junto ao cliente, que cada vez mais se preocupa em consumir produtos e serviços de empresas socialmente e ambientalmente responsáveis.

Se antes o enfoque empresarial no social era feito através da filantropia, a nova visão de responsabilidade social faz com que as empresas busquem por modelos de responsabilidade social melhor estruturados e profissionais. Esse foi o grande direcionador da reestruturação da Rizoma Consulting na área de consultoria.

$\mathrm{Na}$ medida em que a complexidade das ferramentas tecnológicas que estavam sendo usadas para levar a cabo o Projeto Circulação aumentava, os sócios optaram por contratar um gerente, cujo trabalho específico fosse o de acompanhar o uso dessas ferramentas nos projetos desenvolvidos. Foi contratado então o Sr. Fernando Norte, como gerente de desenvolvimento tecnológico. A principal 
tarefa para o qual foi contratado era desenvolver o ambiente virtual do Projeto Guia Acessível. Além disso, ele deveria desenvolver e acompanhar as soluções usadas nos projetos de consultoria, que iam desde o uso de ferramentas relativamente simples, como planilhas e softwares de gerenciamento de projetos, até a programação de ambientes virtuais para acompanhamento pelos clientes,em ASP e Java.

O principal desafio para a tecnologia, no entanto, ainda estava por vir, com a mudança de cidade de um dos sócios.

\section{A questão do conhecimento}

Em 2003, a Rizoma Consulting era composta, além dos sócios, por mais quatro pessoas voltadas para a elaboração do Guia Acessível, pelo gerente de desenvolvimento tecnológico e cerca de 20 consultores-parceiros.

Como toda empresa de consultoria, o principal produto da Rizoma Consulting é o conhecimento. Por isso, os sócios investiram durante muito tempo em cursos, palestras internas e treinamentos para desenvolver metodologias próprias de trabalho.

No período de 1996 a 2001 eles se reuniram com profissionais de diversas áreas, que se tornariam seus consultores-parceiros - como administradores, psicólogos organizacionais, comunicólogos, médicos do trabalho, analistas de sistema, profissionais de RH, contadores, arquitetos, sociólogos e psicossociólogos - para entender qual o papel de cada uma dessas especialidades na empresa. A estratégia da empresa era adquirir habilidade e competência em organizar e coordenar equipes que pudessem funcionar do forma interdisciplinar. A partir das necessidades identificadas na empresa-cliente, os diferentes profissionais seriam alocados para atuar no projeto de consultoria.

Tal filosofia interdisciplinar surgiu da constatação dos sócios de que, por diversas vezes, soluções ligadas a uma área - por exemplo, corte de custos na área financeira - acabavam por prejudicar e ter grandes impactos em outras áreas - como por exemplo, o setor de Recursos Humanos. Assim, se os sócios fossem capazes de identificar as principais necessidades da empresa, poderiam sugerir soluções interdisciplinares que teriam uma eficiência maior e um impacto menor. 
Isso, no entanto, força a empresa a trabalhar sob a perspectiva de small boutique, ou seja, com um teto de três ou quatro projetos simultâneos e com alta personalização dos processos de consultoria. A principal habilidade desenvolvida pelos dois sócios é de montar metodologias interdisciplinares e coordenar equipes cujo perfil individual dos participantes é bastante heterogêneo.

Tais metodologias são desenvolvidas pelos sócios em reuniões nas quais os dois discutem o saber que adquiriram e/ou produziram e suas aplicações práticas. Dessa forma, cada serviço de consultoria passava por um planejamento e elaboração teóricos, que eram repassados aos consultores que o executariam. Os diretores então acompanhavam a implantação e o desenvolvimento de cada projeto, corrigindo desvios técnicos ou metodológicos que porventura aparecessem e encadeando as ações - por vezes antagônicas - de cada especialidade.

Um projeto da Rizoma Consulting, geralmente, atravessa os seguintes passos:

a) Prospecção: Depois de identificada a demanda de consultoria, os dois sócios vão até a empresa apresentar sua metodologia de trabalho e buscar maiores informações sobre a necessidade do cliente.

b) Análise da Demanda: essa fase caracteriza-se por ser um período curto (em geral uma ou duas semanas) em que os sócios observam a empresa, conversando com os principais interessados na consultoria. O principal objetivo dessa fase é realmente validar as necessidades prospectadas inicialmente, garantindo uma adequada compreensão do que deve estar no escopo da proposta.

c) Apresentação e Elaboração da Proposta Inicial: Os sócios fazem um primeiro projeto de consultoria, de diagnóstico organizacional, montando a equipe que participará do projeto. São feitos os convites para os consultores-parceiros e um contrato é firmado com a empresa cliente.

d) Detalhamento do Projeto: Cada especialista faz seu diagnóstico e a equipe se reúne para montar o projeto, integrando todas suas partes. Se for necessário, novos especialistas são convidados para fazer parte. 
e) Execução do Projeto: Um novo projeto é apresentado à empresa-cliente e a consultoria é realizada sob coordenação de um dos sócios. A equipe de um determinado projeto se reúne quinzenalmente para corrigir desvios de percurso.

f) Fechamento e Relatório: Ao final da execução do projeto, um relatório é preparado pela equipe de consultoria para prestar conta das atividades. Como a maioria dos projetos tem caráter bastante qualitativo, uma série de entrevistas de fechamento são marcadas com os responsáveis pelo projeto na empresa, até que os resultados obtidos estejam claros e estratégias de mudança ou de manutenção da mudança sejam traçadas.

A forma de trabalho da Rizoma Consulting levou-a a ter reconhecimento pela excelência de seus projetos. Seu primeiro cliente, uma empresa de transportes, recebeu 8 prêmios no período de dois anos, incluindo o Prêmio Qualidade Rio, oferecido pelo Governo do Estado do Rio de Janeiro, em dois anos consecutivos, e outros prêmios oferecidos por seus principais clientes. Nessa empresa, a equipe era composta por uma psicossocióloga, uma especialista em Recursos Humanos, um especialista em planejamento estratégico, uma comunicóloga e os dois sócios, que coordenavam a equipe.

Também o Guia Acessível foi elogiado pela maioria das ONG's e fundações de Belo Horizonte que tiveram contato com o trabalho nele desenvolvido, incluindo a Coordenadoria de Apoio e Assistência ao Deficiente (CAADE-MG), ligada ao Governo Estadual, a Associação de Pais e Amigos dos Deficientes (APAE-BH e APAE-Contagem) e o ADAPTESE, laboratório especializado em acessibilidade e design da Escola de Arquitetura da Universidade Federal de Minas Gerais - UFMG.

A metodologia de trabalho desenvolvida pela Rizoma Consulting depende basicamente da capacidade de seus sócios-diretores de adquirir conhecimento, integrá-lo, desenvolvê-lo, aplicá-lo na prática e disseminá-lo para os outros membros da equipe.

\section{A mudança do diretor de projetos}

Cientes desta dependência de gerar e desenvolver conhecimento, em outubro de 2002, o Sr. Augusto mudou-se para São Paulo, com intenção de prosseguir seus estudos em pós graduação strictu 
senso (mestrado). Tal mudança foi considerada vantajosa pelos sócios, pois não só ampliaria a rede de contatos para a empresa como agregaria valor por trazer novos conhecimentos, produzidos em um "circuito" diferente da cidade original da Rizoma Consulting. Os sócios consideravam que essa troca de ambiente era positiva para se evitar "vícios de saber”, já que o conhecimento acaba sendo 'filtrado' pelo ambiente que o cerca. Assim, a mudança de cidade poderia aumentar o grau de inovação do conhecimento gerado dentro da empresa, além de ampliar as possibilidades de escolha de técnicas e metodologias.

Nos primeiros meses, o Sr. Augusto fazia viagens constantes para Belo Horizonte, a fim de manter o ritmo de trabalho da empresa. No entanto, após alguns meses, os dois sócios perceberam que os custos relativos a essas viagens eram demasiados para uma consultoria pequena, pois a competição de outras consultorias e, especialmente, de consultores free-lancers, forçavam o preço dos projetos para baixo.

Assim, os dois sócios resolveram diminuir a freqüência das viagens para quinzenal e começar a se corresponder via e-mail. No entanto, faltava ao e-mail agilidade. Conversas que normalmente seriam rápidas passaram a levar muito tempo e o diálogo passou a ser mais formal, acarretando numa diminuição da interação dos dois sócios e, conseqüentemente, da capacidade dos dois de criar soluções. A Sra. Natália acabou ficando sobrecarregada, pois era impossível que o diretor de projetos ficasse todo o tempo on-line para atender os consultores.

A instalação de Internet banda larga nos dois escritórios - em Belo Horizonte e em São Paulo melhorou um pouco a comunicação.

O uso de Messengers foi mais uma opção que os sócios utilizaram para tentar incrementar a comunicação, criando reuniões virtuais com consultores.

Ao mesmo tempo, o problema do gerenciamento do material produzido começou a salientar-se: organizar os diversos e-mails recebidos e enviados, alguns com apenas uma frase de diferença para o seguinte, tornava-se cada vez mais complicado. Os sócios passaram a trocar mais de 30 e-mails por dia 
para resolução de pequenos ou grandes problemas. Além disso, alguns assuntos eram tratados inicialmente em e-mails, depois via messengers, e no final haviam mais e-mails.

O gerente de desenvolvimento tecnológico foi então trazido para a discussão de como minimizar o impacto da distância do sócio na Rizoma Consulting. Para isso, era necessário que ele entendesse o funcionamento da empresa e a lógica da construção metodológica dos projetos no sentido de habiltá-lo a sugerir soluções tecnológicas. Com os questionamentos metodológicos do Sr. Norte, uma questão essencial tornou-se clara: toda a base da metodologia dos projetos residia no conhecimento tácito dos dois sócios, pois suas conversas não eram registradas e os projetos só apresentavam a descrição da metodologia de forma superficial. A maior parte das informações, em especial o conhecimento necessário para a montagem dos projetos e das equipes, além das adequações realizadas e os mecanismos de controle dos projetos, não estavam documentados em lugar algum da empresa.

Sabe-se que a criação de conhecimento, em qualquer área, é um processo iterativo entre o racional e o empírico, entre a análise e a experiência, e entre o implícito e o explícito. Como, então, garantir a continuidade do fluxo de compartilhamento do conhecimento dentro da empresa? Isso significava que os sócios deviam começar a se preocupar com a Gestão do Conhecimento em sua empresa.

\section{Tecnologia como solução?}

A essa altura, os diretores sabiam que sua comunicação via programas Messenger e e-mail não eram suficientes. Eles cobriam somente parte do processo de conversão do conhecimento, ou seja, cumpriam a função de manter o diálogo e interação entre os dois sócios, mas são de difícil ordenação e era necessário um sistema que facilitasse o retorno a discussões inacabadas. Enfim, são programas que auxiliam na comunicação, mas não no gerenciamento do conhecimento como um todo.

Os diretores da Rizoma Consulting depositaram no seu gerente de desenvolvimento tecnológico a responsabilidade de montar um modelo teórico para solucionar seus dois principais problemas: 1) 
aumentar a capacidade de comunicação entre os sócios e deles com outros envolvidos em seus processos e 2) auxiliar na conversão do conhecimento que os sócios acumulavam e criavam sobre os processos. A partir desse modelo, seria necessário viabilizá-lo em uma (ou mais) ferramenta(s) para uso pela equipe Rizoma. O Sr. Norte tinha um desafio nas mãos. 